\title{
The Value of Enterprise Modelling: Towards a Service-centric Perspective
}

\author{
Martin Benkenstein ${ }^{1}$, Michael Fellmann², Michael Leyer ${ }^{1}$, Kurt Sandkuhl² \\ ${ }^{1}$ University of Rostock, Institute for Business Administration, \\ Ulmenstr. 69, D-18057 Rostock \\ ${ }^{2}$ University of Rostock, Institute of Computer Science, \\ Albert-Einstein-Str. 22, D-18059 Rostock \\ \{martin.benkenstein, michael.fellmann, \\ michael.leyer,kurt.sandkuhl\}@uni-rostock.de
}

\begin{abstract}
Enterprise modeling is an important and widespread activity in managing enterprises. A well-founded conceptualization of its value is however missing so far which can be traced back to different understandings of constituents of enterprise modelling. Addressing these different perspectives, we propose to take a service-centric perspective to determine the value of enterprise modelling. We describe the benefits of this perspective and justify our positioning regarding a service-centric perspective.
\end{abstract}

Keywords: Value of Enterprise Modeling, Economic Analysis, S-D logic, Service-centric Perspective

\section{Introduction}

In computer science and information systems development, modelling is an important activity which is used for different purposes, like capturing requirements, visualizing established work processes, specifying system design, expressing information structures, defining variables and their dynamics for simulation purposes, specifying interaction sequences, and many more. In general, the need for modelling is acknowledged and models as a result of the modelling process are established artefacts in systems engineering and development of organizational improvements. In this context, enterprise modelling is used to understand the current situation of an organization, prepare organizational improvements and information systems development or to plan for strategic decision making, to name just a few examples. In general, an enterprise model consists of different perspectives required for the modelling purpose at hand, each focusing on a particular aspect of the enterprise, e.g. processes, business rules, concepts/information, vision/goals, and actors.

Despite this large spectrum of modelling purposes and use cases, the value of enterprise modelling in particular has not yet been subject of extensive research (see Section 2). In this position paper we argue that a new perspective on the value of enterprise modelling is required. Enterprise modelling shows characteristics of the 
service-dominant (S-D) interpretation of services. An example is that S-D logic proposes value creation together with the customer which is the case in enterprise modelling as creation of a model in many cases happens in cooperation between modeller and the enterprise under consideration (cf. section 3 ).

The main contributions are (a) a summary of existing research work on the value of enterprise modelling and why this motivates additional work, (b) an outline of a service-oriented perspective and of work required to address this perspective. The remainder of the paper is structured as follows: Section 2 motivates the need for a value discussion in enterprise modelling, which includes a brief summary of existing work in the field. Section 3 presents initial thought on a service-centric perspective on the value of enterprise modelling. Section 4 gives an outlook on future work.

\section{The Need for a Value Discussion}

\subsection{The Deficit of Works on "Value" and the Lacking Consensus on the Constituents of Enterprise Modeling}

The value of modelling in general and of enterprise modelling in particular has not yet been subject of extensive research A few research activities lead to work on the perceived value of modelling [6], the return on modelling [7], organizational change aspects on modelling [8] and specific economic aspects of modelling (e.g. [5], [23]). The potential benefits of enterprise modelling in various situations in enterprises are a topic in decision sciences, information systems and accounting information systems research (see, e.g., the recent review of [9]). The idea is that the provision of an external model facilitates the evolvement of mental models among decision makers that are necessary to understand the broader picture of decisions and thus make better decisions [10]. However, a comprehensive and generally accepted framework for defining and determining the value of modelling so far has not been proposed.

Among the reasons for this deficit are the different perspectives on "value" and the different perspectives of what is considered as part of "modelling". The scientific literature on enterprise modelling offers several aspects as constituents of enterprise modelling (see, e.g., [4], [3] and [2]), like

- the modelling procedure, sometimes referred to as the modelling method, concerns the way to perform the modelling and the creation of models,

- the result of modelling, i.e. the model, and the value of the model for the organization and the individual,

- the tool support and infrastructure for supporting the use of modelling method or the use of models, and

- the organizational structures and processes establishing modelling within an organization as an organizational task.

However, not all scholars in the field agree on all of the above constituents of enterprise modelling. Some researchers consider constructional and functional structures as part of modelling methods and argue that this cannot be separated [11]. Other scholars emphasize the importance of meta-models and modelling languages 
for capturing different perspectives [12]. Tool support is often seen as inseparable manifestation of modelling approaches and notations [13], but in other research work as aid to support modelling [2]. Organisational structures and role descriptions often are neglected in enterprise modelling approaches.

Due to this plethora of topics and concepts, a recent study among enterprise modelling experts suggests that one of the most important topics of future research has to be research on components of enterprise modelling. "To a great extent, this can be explained in that the variety of different components [...] exhibit a high degree of complexity of the subject area, which needs to be reduced in future research efforts" [14]. Therefore, research should focus on the different types of models, modelling methods and modelling tools.

\subsection{The Need for a New Perspective in the Enterprise Modelling Value Discussion}

The research challenge gets even more complex when taking the definition and measurement of "value" into account. "Value" is considered as "one of the most overused and misused concepts [...] in management literature" [24] that is still subject of scientific debate (e.g., at the VMBO workshop series [25]). Business administration research uses various meanings of the term "value". For instance, accountancy calculates the value of a good based on the costs that incur by its production [15][16], or at times the value of the good is put on the same level with the market price [17][18]. Cost theory identifies the value of a good by analysing opportunity costs [19[. In contrast, business studies that are more oriented towards behavioural sciences regard the value as the value of benefit from the customer point of view. This in turn is differentiated in value in transaction, value in use and value in context [20]. The value in transaction is - from a simplified perspective - identical to the market price. Though, this perspective disregards that customers' willingness to pay is not always identical with the actual price paid. By now, value in transaction is therefore rather defined by the willingness to pay. The value of a good ultimately equals the benefit that arises in the utilization phase of the good, whereas the willingness to pay corresponds to the expectation of benefit that customers assume in the utilization phase. Hence, the willingness to pay does not equal the value in use which cannot be identified until the use of the good has progressed. Further it has to be noted that when identifying the value of the good, the value in use is highly dependent on the context. An enterprise model will likely generate a different value in use for a major corporation than for a small enterprise.

These considerations illustrate that different perspectives are needed for the identification of the value of enterprise models and likewise diverse methods of measurement need to be implemented. While costs and accountancy-driven measurements can easily be done on the basis of cost or market price analyses [16][17], measurements of the value in transaction, the value in use and the value in context may require social-psychological methods (surveys, interviews, experiments) [21][22]. Since such methods measure the value that an individual ascribes to modelling (models, methods or tools), attention needs to be paid to transform such individual valuations to a person-independent organizational or even social level. 
The above situation in research on value of enterprise modelling calls for a change in perspective and a different way of thinking in order to achieve substantial progress in the field. We propose to take a service-centric perspective originating from Service Science, which can be considered as a promising source of inspiration due to its interdisciplinary nature: "Service Science, also known as Service Science, Management, Engineering, and Design (SSMED), aims to be a new, interdisciplinary approach to study, improve, create, and innovate in service" [26].

\section{Conceptualizing the Value of Enterprise Modelling from a Service-centric and Stakeholder-based Perspective}

\subsection{Enterprise Modelling Value from a Service-centric Perspective}

Considering enterprise modelling and its value from a service-centric perspective has substantial innovation potential since it inherently introduces a multi-disciplinary approach due to the multidisciplinary nature of Service Science [26]. This novel thinking disrupts the current situation of disparate, conceptually not aligned and largely incompatible research activities and has the potential to lead to a breakthrough that would not be possible from a mono-disciplinary viewpoint.

The analysis of existing research work showed that so far a service-centric perspective has not been taken when considering the value of enterprise modelling. Vargo and Lusch [1] define services as the application of specialized competences (knowledge and skills) through deeds, processes, and performances for the benefit of another entity or the entity itself. Value considerations in the context of Service Science and the Service Dominant Logic (S-D logic) usually include the potential, process and result perspective on value.

Enterprise modelling shows significant characteristics of the S-D-interpretation of services. S-D logic proposes value creation together with the customer which is the case as the purpose of the enterprise model is to be used by someone and creation of a model in many cases happens in cooperation between modeller and client, e.g. representatives from the enterprise under consideration. From an economics perspective, modelling is information processing as information is gathered, created, transformed and combined. The value and benefits of modelling can be considered from potential (existence of the model, method or tool), process (usage of the model, method, or tool) and result (outcome of the use of a model, method or tool) perspective.

\subsection{Enterprise Modelling Value from a Stakeholder-based Perspective}

The service-centric perspective as introduced in the previous section alone will probably not be sufficient for a holistic view on the value of enterprise modelling since the mutual dependencies and effects of potential, execution and results as well as the organizational management and individual stakeholder perspectives are not sufficiently covered. We have to take into account that different stakeholders value not only the finished enterprise model but also the process of enterprise modelling. The reason is 
that often are members of the modelling team and therefore get insights into the modelling process. We suppose that these insights are also valuable for the enterprise. Thus, the value of enterprise models arises from the model itself but also from the modelling process.

\subsection{Integration of the two Perspectives}

Combining the propositions of the two sections before, we create an integrated view on enterprise modelling value depicted by Fig. 1. It illustrates our proposition to differentiate between various service-centric and stakeholder-based perspectives on enterprise modelling value.

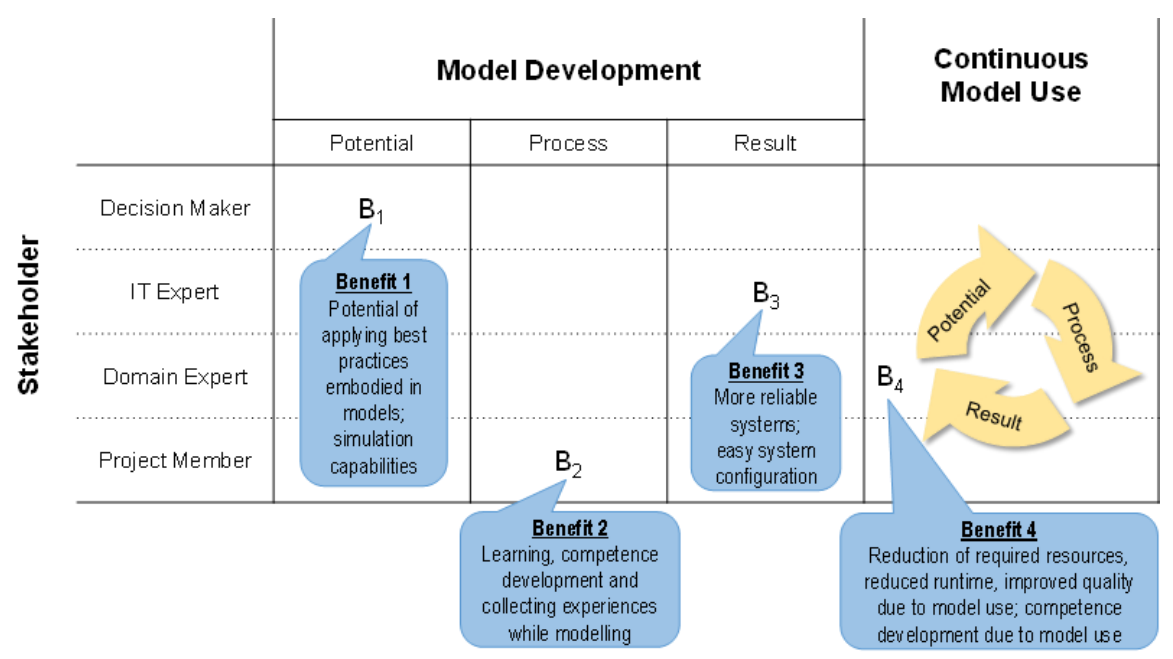

Fig. 1. Enterprise Modelling Value from a Service-centric and Stakeholder-based Perspective

The service-centric perspectives are implemented in the horizontal dimension of Fig. 1. Columns have been structured in two dichotomous areas of model development and continuous model use. Already in the model development-area, it is important to conceptualize the different values according to the service-centric perspectives. In more detail, the potential-perspective covers values at the point in time where a model not (yet) exists, the process-perspective covers values arising during model construction and the result-perspective covers values at the point in time where the model creation has been completed. In contrast to that, in the continuous model use-area, the service-centric perspectives occur in a highly interlinked manner. This is depicted by three arrows forming a cycle in the rightmost column of Fig. 1. It means that each time a model is used, values in all perspectives may occur. In this way, the potentialperspective covers values before a model is used, the process-perspective covers values arising while the model is in use and the result-perspective covers values that can be determined after a model has been used.

The stakeholder-based perspectives are implemented in the vertical dimension of Fig. 1 using one row per stakeholder. Among the stakeholders whose perception of 
value has to be understood are, to take some examples, decision makers in enterprises, IT experts with a focus on enterprise modelling methods and models, domain experts for modelling problems under consideration and members of modelling projects.

\subsection{Examples for Describing Values}

Using our integrated view, different detailed benefits can be described in the cells of the resulting table. Examples for this are shown as $\mathrm{B}_{1}-\mathrm{B}_{4}$ (cf. Fig. 1). In addition, more coarse-grained questions can be raised involving the constituents of enterprise modelling identified in Section 2.1 as a whole, such as:

- Models: How do existing models create value covering the potential value of models, the value in use by employees and the value added as outcome of using models?

- Methods: How is the value of modelling methods composed by the contributions of different method components and what would be approaches for determining the value of a method from a service-centric perspective?

- Tools: How do modelling tools create value covering the potential value of tools, the perceived value in use and the long-term value added as outcome of tool usage?

Moreover, a huge potential for research lies in exploring the value of the whole process of enterprise modelling taking into account the interdependencies between model, method, and tool value and furthermore the moderating and mediating effects of enterprise modelling contexts.

\section{Outlook}

This paper calls for a service-centric and stakeholder-based perspective in determining the value of enterprise modelling. As such, we propose a first high-level proposal how such a value discussion should be structured. Using the proposed integrated view, the following research topics should be addressed:

- Understanding of the determinants of how enterprise models, methods and tools should be designed to provide a maximum of value for decision makers in companies.

- Identification of interdependencies between method-value, model-value and toolvalue (value-in-use).

- Identification of contextual drivers of integrated value creation.

- Understanding of value offer and value creation of a model, method or tool as a whole and the contributions of different constituents to their value (method value model).

The direction of addressing these topics should be to change the view of the scientific community regarding the value of enterprise modelling from a servicecentric perspective. This should include a conceptualization what the value of 
enterprise modelling actually is and this conceptualization has to cover the method or modelling process, the model as an artefact, the tools and organizational context.

The overall aim should be to develop an empirically validated and accepted framework for determining the value of enterprise modelling and its constituents that supports enterprises and method developers. Such a framework can change the way of decision making in what contexts modelling is advisable and contribute to improvement of methods and notations. It would have to come with subsequent methods for determining the actual value and improvement potential of a given enterprise model, method and tool as well as management methods to create and enhance the value of enterprise modelling (concepts for value creation).

\section{References}

1. Vargo, S.L., Lusch, R.F.: Evolving to a New Dominant Logic for Marketing. Journal of Marketing 68, 1--17 (2004)

2. Sandkuhl, K.,Stirna, J., Persson, A., Wißotzki, M.: Enterprise Modeling, Springer, Berlin Heidelberg (2014)

3. Henderson-Sellers, B., Ralyté, J., Ågerfalk, P. J., Rossi, M.: Situational Method Engineering. Springer, Berlin Heidelberg (2014)

4. Frank, U.: Multilevel Modeling. Toward a New Paradigm of Conceptual Modeling and Information Systems Design. Business \& Information Systems Engineering 6, 319--337 (2014)

5. Fettke, P.: Ansätze der Informationsmodellierung und ihre betriebswirtschaftliche Bedeutung: Eine Untersuchung der Modellierungspraxis in Deutschland. Schmalenbachs Zeitschrift für Betriebswirtschaftliche Forschung 61, 550--580 (2008)

6. Indulska, M., Green, P., Recker, J.C., Rosemann, M.: Business process modeling. Perceived benefits. In: 28th International Conference on Conceptual Modeling, pp. 458--471. Springer (2009)

7. Op't Land, M., Dietz, J.L.: Benefits of enterprise ontology in governing complex enterprise transformations. In: Advances in Enterprise Engineering VI, pp. 77--92. Springer (2012)

8. Liberatore, M.J., Hatchuel, A., Weil, B., Stylianou, A.C.: An organizational change perspective on the value of modeling. European Journal of Operational Research 125, 184-$194(2000)$

9. Kelton, A.S., Pennington, R.R., Tuttle, B.M.: The Effects of Information Presentation Format on Judgment and Decision Making. A Review of the Information Systems Research. Journal of Information Systems 24, 79--105 (2010)

10. Sterman J.D.: Business dynamics. Systems thinking and modeling for a complex world. Irwin/McGraw-Hill, Boston, MA. (2000)

11. Dietz, J.L.G.: Enterprise ontology. Theory and methodology. Springer, Heidelberg (2006)

12. Frank, U.: Multi-perspective enterprise modelling. Foundational concepts, prospects and future research challenges. Software \& Systems Modelling 13, 941--962 (2014)

13. ISO/IEC 24744

14. Wirtz, B.W., Pistoia, A., Ullrich, S., Göttel, V.: Business Models. Origin, development and future research. Long Range Planning 49, 36--54 (2016)

15. Weber, J.: Gestaltung der Kostenrechnung, Gabler, Wiesbaden (2005)

16. Plinke, W., Utzig, P., Rese, M.: Industrielle Kostenrechnung. Eine Einführung. Gabler, Wiesbaden (2015)

17. Baetge, J., Kirsch, H.-J., Thiele, S.: Bilanzen. IDW, Düsseldorf (2014)

18. Coenenberg, A., Haller, A., Schultze, W.: Jahresabschluss und Jahresabschlussanalyse, Schäffer-Poeschl, Stuttgart (2016) 
19. Adam, D.: Planung und Entscheidung. Modelle - Ziele - Methoden. Gabler, Wiesbaden (1992)

20. Benkenstein, M., Waldschmidt, V.: Wertkettenanalyse und Service Value. Eine Diskussion im Lichte der Service-Dominant Logic. In: Forum Dienstleistungsmanagement: Service Value als Werttreiber. Konzepte, Messung und Steuerung, pp. 205--221. Gabler, Wiesbaden (2014)

21. Voeth, M.: Nutzenmessung in der Kaufverhaltensforschung. Die Hierarchische Individualisierte Limit Conjoint-Analyse (HILCA). Gabler, Wiesbaden (2000)

22. Kim, J.-Y., Brünner, T., Skiera, B., Natter, M.: A Comparison of Different Pay-per-Bid Auction Formats. International Journal of Research in Marketing 31,368 - 379 (2014)

23. Wolff, F.: Ökonomie multiperspektivischer Unternehmensmodellierung. Gabler, Wiesbaden (2008)

24. Khalifa, A.S.: Customer value: a review of recent literature and an integrative configuration. Management Decision 42, 645--666 (2004)

25. VMBO2016 - 10th International Workshop on Value Modeling and Business Ontologies. http://www.loa.istc.cnr.it/vmbo2016/\#

26. Spohrer, J., Maglio, P.P.: The emergence of service science. Toward systematic service innovations to accelerate co-creation of value. Production and Operations Management 17, $1--9(2008)$ 